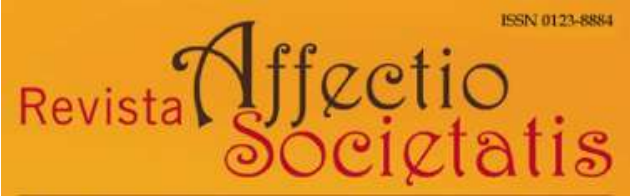

Departamento de Psicoanálisis | Universidad de Antioquia

Revista Affectio Societatis

Departamento de Psicoanálisis

Universidad de Antioquia

revistaaffectiosocietatis@udea.edu.co

ISSN (versión electrónica): 0123-8884

Colombia

La imagen inconsciente del cuerpo en la lectura y la escritura de niños

Revista Affectio Societatis, Vol. 17, N. ${ }^{\circ} 33$, julio-diciembre de 2020

Art. \#4 (pp. 87-111)

Departamento de Psicoanálisis, Universidad de Antioquia

Medellín, Colombia 


\title{
LA IMAGEN INCONSCIENTE DEL CUERPO EN LA LECTURA Y LA ESCRITURA DE NIÑOS ${ }^{1}$
}

\author{
Araceli Colín Cabrera ${ }^{2}$ \\ Universidad Autónoma de Querétaro, México \\ aracolinca@gmail.com \\ https://orcid.org/0000-0002-2730-9628
}

DOI: 10.17533/udea.affs.v17n33a04

\section{Resumen}

En este texto se expone un avance dad, en cada niño o niña, de lo que ha de investigación para destacar la implicación que tiene la imagen inconsciente del cuerpo en el niño, en el aprendizaje de la lectura y la escritura. Algunos psicoanalistas ofrecen sus observaciones e implícitamente dan cuenta de esta relación. Otros la exponen y teorizan explícitamente. La variedad de las dificultades de los niños muestra el trayecto de búsqueda y apropiación de granos de versido su filiación. Planteo que las observaciones pioneras de Dolto sobre la voz, así como los recientes trabajos de Porge, especialmente su propuesta del estadio del eco, nos permiten enriquecer esta relación entre letra e imagen del cuerpo y suscitan nuevos problemas y preguntas.

Palabras clave: imagen inconsciente delcuerpo,letra, voz,lectura,escritura.

\section{THE UNCONSCIOUS IMAGE OF THE BODY IN THE READING AND WRITING OF CHILDREN}

\section{Abstract}

This paper presents a research ad- of the unconscious image of the body vance to highlight the involvement in the child, in the learning of reading

1 En este texto se expone un avance de investigación para destacar la implicación que tiene la imagen inconsciente del cuerpo en la apropiación que hace el niño de la lectura y la escritura. Algunos psicoanalistas ofrecen sus observaciones e implícitamente dan cuenta de esta relación. Otros la exponen y teorizan explícitamente.

2 Docente investigadora de la Facultad de Psicología de la Universidad Autónoma de Querétaro; practicante del psicoanálisis. 
and writing. Some psychoanalysts offer their observations and implicitly account for this relationship. The others expose it and theorize it explicitly. The variety of the children's difficulties shows the path of search and appropriation of grains of truth, in each child, of what has been their filiation. I propose that Dolto's pioneering observations on the voice, as well as Porge's recent works, especially his proposal of the echo stage, allow us to enrich this relationship between letter and body image, and they raise new problems and questions.

Keywords: unconscious image of the body, letter, voice, reading, writing.

\section{L'IMAGE INCONSCIENTE DU CORPS DANS LA LECTURE ET L'ÉCRITURE CHEZ LES ENFANTS}

\section{Résumé}

Ce texte présente le rapport d'avancement d'une recherche dont le but est de mettre en évidence l'implication de l'image inconsciente du corps chez l'enfant dans l'apprentissage de la lecture et de l'écriture. Certains psychanalystes proposent des observations et rendent implicitement compte de cette relation. D'autres l'exposent et théorisent explicitement. La diversité des difficultés des enfants signale la voie de la recherche et de l'appropriation des grains de vérité, chez chaque enfant, de ce qui a été sa filiation. Les observations pionnières de Dolto sur la voix, ainsi que les travaux récents de Porge, en particulier son approche du stade de l'écho, nous permettent d'enrichir cette relation entre la lettre et l'image du corps et de soulever de nouveaux problèmes et de nouvelles questions.

Mots-clés : image inconsciente du corps, lettre, voix, lecture, écriture.

\section{A IMAGEM INCONSCIENTE DO CORPO NA LEITURA E NA ESCRITA DAS CRIANÇAS}

\section{Resumo}

Este texto apresenta um avanço de pesquisa para destacar a implicação que a imagem inconsciente do corpo tem na criança, na aprendizagem da leitura e da escrita. Alguns psicanalistas oferecem as suas observações e implicitamente dão conta desta relação. Outros a expõem e a teorizam ex- 
plicitamente. A variedade de dificul- mente a sua proposta para o estádio dades das crianças mostra o caminho do eco, nos permitem enriquecer de busca e apropriação de grãos de esta relação entre letra e imagem do verdade, em cada menino ou meni- corpo e suscitam novos problemas e na, do que tem sido sua filiação. Pro- questionamentos. ponho que as observações pioneiras de Dolto sobre a voz, assim como os Palavras-chave: imagem inconsciente trabalhos recentes de Porge, especial- do corpo, letra, voz, leitura, escrita.

Recibido: 20/04/2019 • Aprobado: 28/02/2020 


\section{Introducción}

La letra es un objeto de investigación en varios campos: la poesía, la educación, la lingüística, la antropología, la filosofía, entre otros. Pero es desde el psicoanálisis que se ha estudiado su instancia inconsciente, sus modos de insistir, su relación con la identificación y su papel en la subjetivación. El trabajo clínico psicoanalítico con niños, con diversas perturbaciones, ha puesto de relieve el compromiso de la letra en la subjetivación y los desórdenes subjetivos que se expresan en el ámbito escolar. Este artículo es fruto de la experiencia con niños, tanto en la clínica de orientación psicoanalítica como en la investigación participante en entornos escolares. El objetivo de este texto es destacar la relación entre la imagen del cuerpo y la letra, particularmente en la experiencia del niño al aprender a leer y a escribir. La variedad de indicios de esta imagen y sus fantasías concomitantes dan cuenta de la naturaleza de las dificultades en la lectura y la escritura.

Todo aquel que se ocupa clínicamente de niños quizás habrá advertido esta relación que insiste ante el observador. Hay psicoanalistas que lo han referido, unos implícitamente como Dolto (1990/1984) y otros explícitamente como Porge (1987). Reconocer esos indicios es atender a la letra la transferencia en el dispositivo analítico.

El ser hablante desde que nace va haciendo una progresiva aprehensión del mundo del lenguaje. Primero ocurre en su forma auditiva y oral y más adelante participarán otros sentidos en la alfabetización. Ese trayecto corre paralelo a la constitución de su esquema corporal y también a la constitución de la imagen inconsciente de su cuerpo que recorre varias fases. En un primer tiempo el cuerpo se constituye gracias a la resonancia de las voces de padres, tutores, abuelas, niñeras, hermanos. Resuenan los tonos de voz con los que se dirigen al infante. Además de la voz resuenan las palabras, insisten ciertas letras en cada familia. Luego el infante balbucea ciertos fonemas que ha escuchado; los recrea con sus gorjeos y laleos, y especialmente algunas letras de su nombre propio que ha escuchado. En un segundo momento, cuando el niño está en edad escolar, la incorporación de la 
letra ya no será solo por el sonido y sus efectos, sino que participarán la vista y los movimientos que la mano tendrá que hacer para dibujar cada grafía, en niños normo-hablantes. Cada esfuerzo por aprehender el lenguaje compromete su cuerpo y tiene efectos inconscientes sobre él.

Hablar en el dispositivo psicoanalítico produce escritura. Con la voz y la letra se produce una reconfiguración de la imagen inconsciente del cuerpo, sea que la escritura se produzca en el acto analítico o sea que la letra se realice con grafías en papel cuando se trata de la alfabetización o cuando esta escritura implica un intento de historización de la vida de quien escribe. Esto último me ha sido comunicado por amigos escritores que me han relatado algunos sueños. Las fantasías espontáneas de los niños comunicadas en juegos con imágenes y letras dan cuenta del modo como participa la imagen inconsciente del cuerpo en el proceso de alfabetización. Las fantasías de los niños ofrecen un material para analizar, en cada caso, porqué se les complica aprender a leer, como se verá adelante; a veces esas comunicaciones resultan enigmáticas, otras veces son muy elocuentes aún si son indicios. Gradualmente el niño va constituyendo un tejido para explicarse dónde está situado en su realidad familiar, aunque en su mayor parte este tejido transcurre inconsciente para el propio niño. Si el niño tiene muy pocas pistas de lo que sus padres quieren de él es muy probable que su acceso a las letras se vea dificultado. Tener alguna noción de lo que los padres esperan de él es muy importante. También ocurre que niños que no son escuchados por sus padres tengan mayores dificultades. Esto no es una regla porque cada situación es compleja y diferente.

Emilia Ferreiro (2007) ha estudiado las hipótesis que los niños tienen con la lectura y la escritura y las ha agrupado en varias fases que son más o menos universales. Aquí haremos un acercamiento desde lo singular, donde los tiempos lógicos, en el sentido de Lacan, (2009/1945, págs. 193-208) son tiempos de constitución de la imagen inconsciente del cuerpo. El niño requiere de la apropiación de ciertas letras para su subjetivación, sean estas letras de su nombre llamado de pila, sean de sus apellidos. 
Estas dificultades no pueden ser comprendidas sin la consideración del entorno social, económico y político y del sistema educativo. Estos aspectos se traducen en discursos que no son coherentes entre sí. Estas observaciones clínicas, y lo que de ellas se deriva, no se pueden extender a todos los niños en dificultades, pero acaso nos aporten claves para situar, en un futuro, algunas relaciones hipotéticas entre la dimensión subjetiva y el orden social cuando de leer se trata. Esperamos que puedan ser herramientas para acompañar a ciertos niños con trastornos o impasses en su subjetivación. Todo ser hablante se sirve de la letra aunque no sepa leer ni escribir. En las culturas oyentes, lo que más importa de la letra, en primera instancia, es su sonido. La letra encuentra subrogados cuando no hay grafía. Las culturas ágrafas, por ejemplo, sostienen su sistema simbólico en la dimensión sonora de la letra y en lo que se organiza en torno a ella. La cultura sorda localiza el subrogado de la letra gráfica en la lengua de señas de naturaleza visual; en ella es muy importante la intención del gesto, la actitud además del código. Los invidentes localizan la letra tanto a nivel sonoro como en el sistema Braille. Me refiero con letra a la noción lacaniana, es decir, a la organización metafórica y metonímica de su insistencia, descubierta por Freud y destacada por Lacan como la piedra angular de su discurso (2009/1957, págs. 461-495). Se dice letra en singular pero compromete a muy diversas formas de retorno, sustitución, elisión, omisión, desfiguración, etc. Una sola letra puede ser representante de un grupo de ideas complejas, como lo revela el lapsus o el rébus del sueño (Freud, 1979/1900, págs. 285-286). El rébus es una imagen acertijo que hace la función de letra (s).

El contenido del sueño nos es dado, por así decir, en una pictografía, cada uno de cuyos signos ha de transferirse al lenguaje de los pensamientos del sueño. Equivocaríamos manifiestamente el camino si quisiésemos leer esos signos según su valor figural en lugar de hacerlo según su referencia signante. (Freud, 1979/1900, pág. 285).

He integrado aquí observaciones de distintos tiempos de mi experiencia, unas recientes y otras de larga data. Quizás la mayoría de las respuestas son de larga gestación, en la cual participa también el azar y la propia subjetividad del investigador. Me apoyaré en desarrollos 
clínicos y teóricos de psicoanalistas, entre los que destacan: Freud, Dolto, Lacan y Porge. El de Freud se refiere a cómo operan las letras en las formaciones del inconsciente: chiste, lapsus, olvidos o actos fallidos, sueño, síntoma. En cada caso se encontró con letras y formas sustitutivas fragmentadas hechas de letra. La teorización de Dolto sobre la imagen inconsciente del cuerpo, seguramente fue su aporte más importante. Aunque fue tardía su formalización (1990/1984), encontramos esbozos previos desde sus primeras intuiciones y observaciones en viñetas y casos. Es llamativo que teoriza sus hallazgos 3 años después de la muerte de Lacan. Él ofreció que algún día escribiría un texto sobre el invento de la muñeca flor, y eso no ocurrió. Lacan no reparó en la aportación que ella hizo (Dolto, 1985/1949, pág. 23). La noción de letra fue desarrollada por Lacan (2009/1957, págs. 461495) y diferenciada progresivamente del significante. Evidentemente las nociones en un autor y en otro no son las mismas y tampoco se mantienen intactas con el paso del tiempo; la teoría se cuestiona y renueva permanentemente en función de la praxis. La noción de escritura en psicoanálisis tiene un sentido más amplio que en el ámbito educativo o literario y no necesariamente implica papel y grafías, pero ciertamente no se hace sin la letra.

\section{Antecedentes}

El funcionamiento de la letra en lo inconsciente lo descubrió Freud. Dejó un legado de numerosos ejemplos para mostrar la fragmentación de las letras y el retorno sustitutivo de letras que se han olvidado. Los encontramos en su obra sobre los sueños (1979/1900) (1984/1900), en su obra del chiste (1986/1905), en su obra sobre la psicopatología de la vida cotidiana (1986/1901) y a todo lo largo de su escritura en muy diversos casos clínicos a propósito del síntoma. Freud no se refiere a letras en el sentido exclusivo de grafías sino a letras que se pronuncian. Esto comprende tanto la dimensión sonora de la letra en su emisión vocal, entre lo que se quiso decir y lo que se escuchó, como su representación escrita. También ocurren lapsus y omisiones al escribir, sea porque se escriba una palabra por otra, una letra por otra o se omita alguna sílaba o palabra. 
Freud se preguntaba por qué olvidamos frecuentemente los nombres de personas, de autores, de lugares, es decir los nombres propios. En su obra "Psicopatología de la vida cotidiana" (1986/1901, págs. 9-15) ofrece un cuerpo numeroso de ejemplos de diversas operaciones fallidas, entre ellas está el olvido de nombres propios, que por su importancia encabeza la lista. En uno de esos ejemplos, él iba de viaje y conversaba con otro viajero sobre el tratamiento que dan a la sexualidad y a la muerte los turcos de Bosnia y Herzegovina; de pronto se dio cuenta que asoció con algo muy penoso que no le quería compartir a ese desconocido y rechazó la ocurrencia; luego intentó recordar algo que sí le quería decir, el nombre de un pintor, y hete aquí el olvido, se trataba de Signorelli, quien pintó unos frescos en la capilla de la Catedral de Orvieto sobre el juicio final, por eso el nombre del pintor se conectaba asociativamente con la muerte y, por ende, con el pensamiento penoso que no quería compartir: el suicidio de un paciente suyo por una incurable perturbación sexual. En lugar del tema rechazado, olvidó el nombre propio del pintor. En primer lugar, llama la atención que este nombre propio olvidado empieza con "Sig", como las tres primeras letras del nombre de Freud, Sigmund. Comenzó a buscar en su memoria el nombre olvidado y retornaban nombres sustitutivos que descartó: Boticcelli, Boltrafio; Signorelli reapareció fragmentado en dos palabras, Signor, que en italiano significa señor, y elli, homófono de Eli, que en hebreo significa Dios mío; "elli" es la terminación de Signorelli. No retomaré todas las sustituciones que Freud analizó, justo en un juego metonímico, por razones de espacio, de las que hace un pormenorizado análisis destacando los nexos de cada sustitución con el nombre olvidado y con el tema de la conversación (Freud, 1986/1901, pág. 12). La serie de sustituciones Signor, Her(r) (señor en alemán), elli, son traducciones y van por el lado del sentido, mientras que Sig (que está presente en Signorelli y en Sigmund) está del lado del sinsentido de la letra.

En su obra sobre el chiste no es menos evidente la importancia que reviste una letra en su diferencia con otra para hacer jugar el efecto chistoso. Ahí el fonema transporta la letra y en las técnicas del chiste la letra cobra un valor capital. Pero en psicoanálisis la letra no se puede analizar sola ni aislada, siempre es embajadora de una madeja de ideas complejas. En el chiste analizó cómo una sola letra, 
justo por no tener un sentido, puede remitir a otra escena, a otro contexto. Y es así que la letra es soporte de la expresión de contenidos inconscientes. Con el chiste se preocupó por dilucidar más de doce técnicas del mismo.

Los nombres propios aparecían con frecuencia en los chistes. Veamos un ejemplo que le contaron a Freud: una señora se queja: "Usted me ha creado la expectativa de conocer a un pariente de Jean Jacques Rousseau, acaso un pariente espiritual y en cambio veo a un Roux sot, (pelirrojo tonto)" ("Vous m'avez fait connaître un jeun homme roux et sot, mais non pas un Rousseau") (Freud, 1986/1905, págs. 30-31).

\section{Roussau}

\section{Roux sot}

Estos dos términos son homófonos. Curioso que Freud los ponga separados por una barra como el signo saussuriano, o más propiamente como el primer movimiento de inversión que pensó Lacan, el contenido reprimido está abajo. Es una crítica no explícita, "rojo tonto" en lugar del apellido Rousseau, que provoca risa por el ingenio de su homofonía.

Otro ejemplo que refiere Freud reza así: El primer Napoléon Bonaparte en un baile le dice a una dama italiana, refiriéndose a sus compatriotas. "Tutti gli Italiani danzano si male», "Todos los italianos bailan tan mal"; y ella replicó con prontitud: "Non tutti, ma buona parte», "No todos pero sí buena parte". (Freud, 1986/1905, pág. 32). Buona parte es casi homófona de Bonaparte.

Otro chiste con un nombre propio: Marie Wilt era una cantante europea famosa por su amplitud de voz y de figura. Quienes hacían de su figura un chiste hacían jugar su apellido Wilt con la palabra alemana Welt que significa mundo. En lugar del título de la novela de Verne, "La vuelta al Welt en 80 días", sería "La vuelta a Wilt en 80 días" (Freud, 1986/1905, pág. 73). 
Cuando Freud habla de ejemplos, lo reprimido son letras. Cuando teoriza llamó Vorstellungrepräsentanz (representante de la representación) al núcleo de lo inconsciente (1984/1915, pág. 173). Deduzco que la letra es para Freud la Vorstellungrepräsentanz. La letra es el soporte del sinsentido y sin su inscripción no sería posible la procuración del sentido que busca el yo. Pero en la metapsicología solo dice que en lo inconsciente no hay sino representantes de la representación, algo que está fuera del sentido pero que es materia prima para su procuración.

Por su parte Dolto, a diferencia de Porge, no teoriza la relación entre letra e imagen inconsciente del cuerpo. Pero sus casos hacen visible esta relación. Se encuentra en muy diversos lugares, entre ellos, en su libro En el juego del deseo (1981), y en diversas viñetas como la de Gilles (1990/1984, p. 46) y Federico (1990/1984, págs. 40-42).

\section{Las preguntas}

¿De qué da cuenta la imagen inconsciente del cuerpo? ¿Qué significa que la imagen inconsciente del cuerpo está comprometida en la alfabetización de los niños? ¿De qué manera el clínico puede estar advertido de esta imbricación para atender mejor la transferencia, orientar mejor la escucha y la observación del niño? En mi experiencia, he observado de modo insistente que la imagen inconsciente del cuerpo está comprometida con la lectura y la escritura de niños pequeños entre 4 a 7 años. Algunos padres de estos niños han consultado por problemas de sus hijos para leer o para escribir y en otros casos es una manifestación que acompaña otros motivos para solicitar la atención psicoanalítica al niño.

Hay preguntas que solo se pueden contestar caso por caso, niño por niño, atendiendo a su singularidad. La letra es un patrimonio cultural material. Conecta lo social, lo político y lo subjetivo con el cuerpo, y con ella se tejen las subjetividades. 


\section{El enigma del nombre reside en la letra}

Cada ser humano porta un enigma en su nombre propio que está relacionado con la verdad inconsciente del por qué vino al mundo.

El ser-hablante en cuestión se reparte, por lo general, entre dos hablantes. Dos hablantes que no hablan la misma lengua. Dos que no se escuchan hablar. Dos que no se entienden, sin más. Dos que conspiran para la reproducción, pero de un malentendido cabal, que transmitirán con dicha reproducción. (Lacan, 1980, 10 de julio. La traducción es mía).

En cada ser humano hay un continente de cosas no dichas que precedieron a su nacimiento. El cuerpo no hace aparición en lo real sino como malentendido y es fruto del linaje (Lacan, 1980, 10 de junio. La traducción es mía). Algo, muy poco, una brizna apenas de ese malentendido de los padres será recogida por la lalangue y con eso el niño va a tejer su cuerpo. La lalangue es un neologismo para designar complejas operaciones subjetivas a cuyas manifestaciones la psicología llama laleo. Así, las letras repetidas, balbuceadas, morderán la carne del infante, gracias a lo cual podrá ser un ser hablante. Es porque su lugar en el mundo es único e irrepetible que aportará al mundo una mirada, un decir, únicos y nuevos. Las letras del nombre propio serán el cimiento de lo inconsciente, lo reprimido primordial, gracias a lo cual podremos ser seres hablantes y pensantes. El niño escucha su nombre a veces antes de nacer y de saber que ese nombre lo designa a él. Lo escuchará muchas veces en los primeros meses de su vida, más tarde buscará apropiarse de él; por algo se lo llama "nombre propio", pues su apropiación tiene efectos inconscientes. El nombre produce cohesión narcisística, es un objeto metonímico; en el caso Signorelli tenemos un ejemplo de la metonimia. Los chicos de secundaria son muy hábiles con el albur, se sirven de la metonimia para poner apodos a sus compañeros, un apodo deriva en otro más ingenioso. El deseo danza en la metonimia. Con ese nombre los padres designan a su hijo o hija. Hay muchos nombres propios que se repiten, pero cada uno de ellos entrará en relaciones distintas con el discurso de cada familia, y sobre todo estará comprometido con la opacidad de la 
combinatoria del deseo de los padres y el por qué trajeron a ese hijo al mundo. El niño preescolar sabe que su nombre se escribe con letras y muestra gran interés en identificarlas, al menos la primera letra de su nombre. Eso reprimido primordial es fundamental para que se puedan producir pensamientos, frases y toda producción creativa y de sentido que un ser humano pueda hacer a lo largo de su vida. Esto ha sido descubierto por la clínica psicoanalítica. En esta hemos advertido que los problemas de escritura y comprensión lectora de niños y jóvenes están ligados a una verdad inconsciente y que, localizada esta, el síntoma "escolar" desaparece. Las imágenes de fragmentación del cuerpo son anteriores al Estadio del espejo, como lo refirió Lacan (2009/1949, págs. 102-103; 2009/1936, págs. 109-111). Cuando la subjetivación de los niños transcurre en soledad, en "compañía" de otros hermanos, pero con ausencia de los padres, esos tiempos de constitución son muy relativos y presentan muchas variaciones.

\section{La imagen inconsciente del cuerpo}

La imagen inconsciente del cuerpo es una noción que fue desarrollada por Dolto y da nombre a uno de sus libros escrito pocos años antes de morir y publicado en 1984 (1990). Las aportaciones más importantes de un autor no se tejen sin su historia de vida. Siendo ella aún infans, perdió a su niñera y se enfermó gravemente, según refiere en sus memorias. Su niñera era cocainómana. Cuando los padres se enteran que llevaba a la niña Dolto bebé al hotel, a adquirir la droga, la despiden. Dolto, de meses de nacida, hace una crisis respiratoria que la puso al borde de la muerte. El tracto respiratorio no es cualquier zona para un cocainómano. Dolto planteó que el infante no sabe que tiene un rostro, asume el rostro del otro como el propio. De adulta, la pérdida de esta niñera le dio una clave para considerar una primera imagen de base, que es el tracto digestivo y respiratorio. Su modo de vivir su infancia le llevó a interesarse por la pediatría y luego por devenir psicoanalista.

Ella distingue esquema corporal, que es universal, de la imagen inconsciente del cuerpo, que es absolutamente singular, definida como "[...] la imagen potencial de comunicación en un fantasma" 
(Dolto, 1990/1984, pág. 31). Esta noción es muy cercana a la noción de cuerpo en psicoanálisis planteada por Lacan; solo que Dolto hace consideraciones importantes que se derivan de su enorme experiencia clínica como pediatra y luego como psicoanalista con niños de muy diversas edades. Propuso que la imagen inconsciente del cuerpo se constituía en los 3 a 4 primeros años de vida, a lo largo de tres momentos. Las imágenes son 1) imagen de base, 2) imagen funcional, 3) imagen de las zonas erógenas (1990/1984, págs. 42-52). Las imágenes se tejen con cuatro tipos de experiencias: olfativas, visuales, auditivas, táctiles, que se seleccionan por su significatividad. Por un lado, habla de 3 imágenes que se suceden, entretejen y articulan a lo largo de la primera infancia del niño, y por otro lado marca una distancia y diferencia con Lacan porque considera la dimensión especular no solamente para la imagen óptica del espejo, sino para otros registros, en especial la voz, como ya hemos mencionado antes. Eso constituye un adelanto de varias décadas a lo que luego plantearía Porge como Estadio del Eco (2012).

La muñeca flor es una muñeca de trapo que ella encargó a una costurera como un recurso para el juego de los niños que ella atendía. En lugar de la imagen de un ser humano es una flor, con tallos, hojas y corola. No hay articulaciones, ni pies, ni codos, ni cabeza. Al compartir con psicoanalistas su invento, Lacan afirmó que tenía el sentimiento de que eso guardaba relación con su estadio del espejo. En respuesta Dolto afirma que sí, en efecto, pero agrega que lo especular no es solo de naturaleza visual. "[...] hay que entender la idea del espejo como objeto de reflexión, no sólo de lo visible, sino de lo audible, de lo sensible, de lo intencional" (Dolto, 1985/1949, pág. 23). Lacan busca inscribir esa invención en sus propios aportes. Ella plantea una crítica implícita a la formulación del estadio el espejo; ella va más lejos y prefigura con 70 años de anticipación lo que luego se llamaría, según Porge, estadio del eco (2012, págs. 57-93). Lo que es llamativo es que cuando ella comunica su cuestionamiento ante Lacan y discípulos, parece no tener efectos. El eco no se produce. Lacan no parece haberlo oído. No rectificó nada a la luz de esta observación.

La noción de Dolto rebasa temporalmente el estadio del espejo de Lacan y hace participar en la reflexión de la imagen a otras vías per- 
ceptivas. La teorización de Dolto sobre lo especular no se puede ajustar a las cuatro formas del objeto $a$ de Lacan. Término este con el que Lacan designó al objeto causa de deseo (pecho, heces, mirada y voz) (Lacan, 1963, 19 junio). Ella no dice que existan otras formas del objeto $a$, pero considerar lo táctil y lo intencional hace girar lo especular en otras coordenadas. Lo táctil y la voz no tienen las mismas propiedades, lo que dio lugar a que Lacan redujera a cuatro las formas del objeto $a$ y su diferencia con Dolto da lugar a otra reflexión detenida sobre esa cuestión que rebasa los propósitos de este artículo.

Una identificación se va a revelar clínicamente en el decir del analizante y desde luego que está ligada a la imagen inconsciente del cuerpo. La imagen potencial que emitirá el niño con su voz y sus palabras en una cadena asociativa, la expresará con dibujo y juego, o sin ellos. En la constitución de la imagen inconsciente del cuerpo no solo participa el estadio del espejo sino también el estadio del eco que precede al espejo, lo acompaña y lo rebasa. Es decir, el estadio del eco aparece antes del estadio del espejo, durante el mismo y después del mismo (Porge, 2012, pág. 78). Y si recogemos la advertencia de Dolto, lo visto y lo escuchado se integrarán con otras formas sensoriales en el tiempo y en el espacio.

En el trabajo que hace Porge en Voix de l'Echo (2012) para proponer un estadio del eco, recoge dos observaciones que son muy pertinentes para mostrar que la voz por su parcialización en el eco está más comprometida con la letra que la imagen jubilosa en el espejo. A propósito del mito de la ninfa Eco y de Narciso refiere a Jaeglé, que dice: “[...] los redoblamientos de la voz de Narciso en la voz de la ninfa Eco significan que un cambio de sexo acompaña al fenómeno del eco" (Jaeglé citado en Porge, 2012, pág. 78, la traducción es mía). Porge comparte otra observación de Fréderic Pellion:

Con Eco hay un redoblamiento de la voz de Narciso, con el espejo del agua hay un redoblamiento de la imagen. No son los mismos redoblamientos. Se conjugan pero no son equivalentes. Uno concierne a la imagen, a la apariencia, el otro al sonido, a la palabra. Uno está totalizado (la imagen de conjunto), el otro está parcializado (el eco de una parte de las palabras). Por otra parte, hay dos mo- 
vimientos en sentido contrario: Narciso se acerca a su imagen, Eco se aleja de lo emitido. (Porge, 2012, pág. 78, la traducción es mía).

La totalización de la imagen permite producir un yo.

En el hecho de que el eco sea parcializado reside su importancia. El niño que está en proceso de leer parcializa las sílabas o las letras, o bien escucha la parcialización de los sonidos cuando el adulto las separa por sílabas. Es un momento de integrar de otra manera el eco con lo que mira y con lo que lee. La escritura es un objeto cultural del que el niño se apropiará y con las letras se lee y se escribe su nombre propio. El niño va a deducir que su nombre está contenido en ese cuerpo de letras con las que se nominan las personas, los objetos del mundo y las relaciones entre ellos. Y habrá voces y palabras o sílabas que recogen parcializaciones producidas en el estadio del eco, con todo lo que ello implica.

Laleo, gorgeo y balbuceo del infante para la psicología solo son un comportamiento observable que prepara al niño para adquirir el lenguaje. Para Lacan es un tiempo y un ejercicio con el que ocurren complejas operaciones subjetivas; llamará a este tiempo con un neologismo involuntario resultado de un lapsus: la lalengua. Se escribe así junto para distinguirlo de la lengua de Saussure. Es un modo de comunicación con la madre, una protolengua con ella. La produce para invocarla lúdicamente cuando no tiene tensiones. Es un ejercicio de goce de lo que es imposible de decir. Crea alteridad por la forma de resonar los sonidos deformándolos (baby talk). La lalengua forma parte del estadio del eco. La fragmentación del eco y su resonancia producen un cuerpo para integrar al ser hablante en la filiación. Propongo una tesis: que en la alfabetización se produce una reescritura de la lalengua y con ella una reconfiguración de la imagen inconsciente del cuerpo. Es un tiempo de fragmentación de los sonidos con las grafías y las sílabas.

Comentaremos ahora una viñeta de Dolto que intitula "Federico". Se trata de un niño que no podía leer y escribir y presentaba un grave trastorno subjetivo (1990/1984, págs. 40-42). Ella observaba que en sus dibujos había una letra A que dibujaba de cabeza y como sin relación con su dibujo. Dolto pregunta si es una letra "A", el niño 
lo confirma con un sí inspirando en lugar de emitir la voz. El niño no sabía por qué repetía esa letra, Dolto tampoco. Pregunta a los padres adoptivos y se entera que Armando era su primer nombre antes de la adopción. Ella lo llama por ese nombre “¡Armando!” “iArmando!”, sin mirar al niño, en todos los tonos de voz y dirigiéndose a diversos rincones del espacio, buscando un cuerpo que se llame Armando hasta que se encuentra con la mirada del niño y le dice: "Así te llamaron tus primeros padres: Armando". La mirada del niño se ilumina. La nominación con tonos de voz muy diversos, desafectivizados, como quizás lo llamaban en el orfanato, produjo la integración de las dos imágenes de su cuerpo, la anterior a su adopción asociada con el nombre de Armando y la posterior imagen de su cuerpo, la asociada al nombre Federico que le pusieron sus padres adoptivos. Después de su genial intervención en acto con el niño, algo se pone en marcha de modo que en breve tiempo el niño puede leer y escribir. La voz (con aliento inspirado) retiene lo que no ha sido inscrito, la voz retenida hace de archivo a la espera de que algo sea reconocido. Dolto dedujo que ahí residía una clave importante: la dislocación de su imagen corporal estaba sostenida por la letra A de su primer nombre, anterior a su adopción. La voz en su resonancia se hace letra. Y la letra es un borde de la falta (Porge, 2015). La falta se mueve de lugar gracias a la enunciación. Por su forma de escuchar a la letra, Dolto sigue las enseñanzas de Freud y de Lacan.

\section{La lectura, las zonas erógenas y la fantasía}

El organismo tiene agujeros a través de los cuales incorporamos y expulsamos sustancias sin lo cual la vida no sería posible. En el origen de la vida y por la condición prematura del infante la madre manipula su cuerpo para asearlo, cambiarlo y también para gozar con el cuerpo del infante. Se dice, por ejemplo "este bebito está para comerlo", es objeto de goce. Esta noción de "comerlo" es metafórica para la madre, pero no para el infante. Esos agujeros son privilegiados para devenir zonas erógenas. Una zona erógena es un agujero del cuerpo o la piel que se erogeniza por el contacto con otro ser humano (Freud, 1978/1905, VII, pág. 166), como es el caso de la boca 
en el beso. Esta erogenización se inicia con la boca del infante y el pezón de la madre. Hay zonas erógenas privilegiadas como el ojo, el oído y la boca, lugares a través de los cuales nos comunicamos con el mundo y recibimos de él palabras, escenas, mensajes, intenciones, actitudes, etc. Luego el niño comerá con las manos. Con el modelo de la incorporación del alimento el niño pasa por momentos en que "se come las letras". En efecto, según señala Porge, el niño tiene necesidad de incorporar ciertas letras de su apellido paterno (1987, págs. 125, 127), eso forma parte de su subjetivación, es otro tipo de "nutrición". La letra es el litoral de la falta en el saber; es litoral entre saber y goce (Lacan, 2012, págs. 22, 25).

En el caso de la escritura, además del ojo, el oído y la boca, también se pone en juego la mano y la lateralidad. El oído del niño percibe los tonos de voz y los percibía desde que era un infante y aún no entendía nada. Y por el tono de voz significará la intención del adulto, además de entender las palabras. Esas intenciones de otro tiempo (cuando era infans) se reactualizan con ciertas palabras, comenzando por su nombre y lo que está asociado de manera inconsciente a este. Voz y palabra son dos registros muy diferentes. La voz no tiene sentido, pero sí tiene significación según su inflexión, su modulación, su tono, su timbre, su carácter evanescente. Es por la voz que se registra el deseo del Otro. La voz es el vehículo de los significantes, diría Lacan en su Seminario 5 (sesión 23 abril 1958) cuando aún no diferenciaba bien la letra del significante.

¿Qué quieren de mí mis padres? El ojo y el oído son zonas erógenas muy importantes para la producción de fantasías en la infancia. Estas fantasías infantiles permanecerán inconscientes. Lo que se mal-escuchó por diversas razones, entre ellas por no conocer el sentido de las expresiones adultas, dará lugar a creaciones de sentido fantasiosas. Alguna escena que el niño observó, pero no comprendió, también dará lugar a fantasías.

Los ingredientes de la fantasía son restos de cosas vistas y de cosas escuchadas. Freud descubrió que la fantasía opera un cruce entre lo que se cree haber visto y lo que se cree haber escuchado (1986/1897a, pág. 293). Esto es bien evidente cuando le contamos un cuento al niño. 
Más allá de las imágenes que el cuento tenga, el niño al escuchar crea otras imágenes en su mente. Y estos trayectos también serán recorridos. Lo no ligado de la vivencia de satisfacción y de la vivencia de dolor será materia prima de la fantasía que aparecerá hacia el sexto mes de vida (Freud, 1986/1897b, p. 285). Mal escuchar las palabras a la letra induce fantasías sádicas, como en el caso que menciona Dolto en un ejemplo (rabattre por battre/ bajar por pegar) (1981, pág. 19). Durante la alfabetización, el niño hace una nueva "conquista" del lenguaje y con este accede a un legado, tanto de su cultura como de su familia. La lectura pone en juego tres zonas erógenas, el campo de lo escópico (mirada), la dimensión oral y el oído (implican también tres tiempos de la pulsión invocante: escuchar, ser escuchado y hacerse escuchar). Porge señala que la pulsión invocante es quizás la más importante de todas y la única que compromete dos zonas erógenas, por eso propone un grafo de la pulsión con doble torsión: oído y boca.

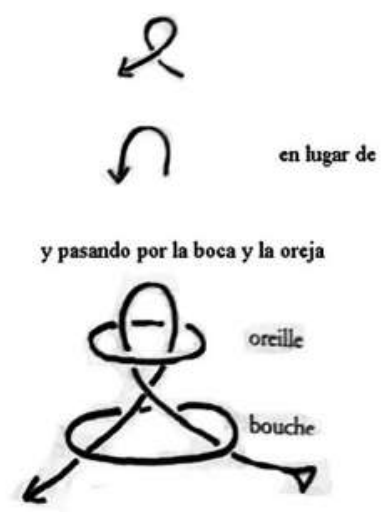

Figura 1. Grafo de la pulsión invocante.

Fuente: Porge, 2011, pág. 25.

Cada zona erógena se va a entretejer con muy diversas fantasías. Si las fantasías del sujeto comprometen sintomáticamente estas zonas erógenas (ojo, boca, y oído), el niño no está en condiciones aún de realizar un trabajo sin dificultades con la letra. Esto no se puede generalizar, es altamente singular. Eso depende también del lugar en que la madre y el padre ponen a su hijo en la dinámica familiar. Saber de ese lugar es indispensable y anterior a cualquier otro saber. 
Si la sublimación existe, está ligada a una pérdida que se produce en el segundo tiempo del juicio, a partir del cual se podrán, quizás, escribir otras pérdidas posteriores. Las palabras están en ausencia de las cosas. También puede ocurrir que su estructuración subjetiva dé lugar a que no pueda integrar una imagen de su cuerpo como un cuerpo al que le falta algo. En el origen de la vida el infante cree ser uno sólo con la madre. Sólo más tarde se percatará que ella no es parte de su ser. Esta operación de separación y producción de falta también depende del lugar que los padres dan a un hijo.

El juego produce una reconfiguración de la imagen inconsciente del cuerpo; pacifica las pulsiones agresivas y autodestructivas y abre vías para la incorporación de la letra. El juicio es fundador del psiquismo humano. Freud formula en su "Proyecto" (1986/1895, págs. 372383 y 413-436) los dos tipos y tiempos del juicio: juicio de atribución y juicio de existencia. Sobre el semejante el infante comienza a pensar, a separar lo que le causa placer y lo que le causa dolor, lo que es bueno para él y lo que quiere expulsar de su ser porque le hace mal. Si este primer juicio no se ha producido, no se puede organizar un yo incipiente. Luego retoma el tema en su artículo "La negación" (1984/1925, págs. 251-257). El segundo juicio le implica al niño reconocer la realidad, el objeto que le produce placer es el mismo que le produce dolor.

Dolto muestra lo ocurrido con la muñeca flor en el caso de las niñas Bernardette y Nicole (1981, págs. 129-184). Esas niñas proyectaron su kakón (el mal) sobre la muñeca flor. Esta operación les permitió a ambas niñas separar lo bueno de lo malo para luego reintegrarlo en una nueva operación del juicio, la del juicio de existencia; e incluso le permitió a Nicole poder destruir con ayuda del padre a ese juguete (mona del zoológico) que se hizo depositario de su propio mal. El ceremonial "ritual" que hace Nicole en su casa es impresionante. Esto recuerda los rituales africanos de algunas comunidades llamadas "primitivas". Cuando yo releo estas viñetas no puedo dejar de pensar en lo dicho por Freud sobre los tiempos del juicio. Lacan analiza con Hyppolite (2009/1954a, págs. 351-361; 2009/1954b, págs. 363-378) estas dos operaciones. Hyppolite (Lacan, 2009/1954a, págs. 837-846) piensa las dos operaciones del primer juicio como realizadas en un tiempo mítico (Einbeziehung/ Autossung). En el segundo juicio apa- 
rece la negación (Bejahung/Vernienung), piensa a esta última como algo más que pulsión de destrucción, pues es generadora del símbolo (2009/1954, pág. 844). Presenta al ser bajo la forma de no serlo. El símbolo es en sí mismo el reconocimiento de algo que no está, que se ha perdido (Freud, 1984/1925, pág. 256). Y la pulsión invocante requiere de esa pérdida para que ahí el niño, en ese lugar de falta, pueda invocar lo ausente.

La alfabetización encuentra mayores dificultades cuando la pulsión invocante no se ha producido en una primera vuelta, aunque sabemos que la castración se está efectuando a lo largo de la vida.

\section{La voz y la letra}

El papel de la voz, como un elemento morfogénico del cuerpo, y no solo la mirada, permite establecer la íntima relación que guardan el estadio del espejo con el estadio del eco propuesto este último por Porge (2011, págs. 7-28; 2015, págs. 109-124).

La intrincación entre estadio del eco y estadio del espejo que propone Porge (2012, pág. 78) tiene efectos sobre el esquema siguiente:

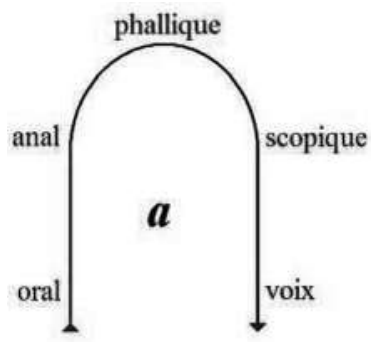

Figura 2. Esquema de la sesión del 19 de junio de 1963, Séminaire 10, L'Angoisse.

Fuente: Lacan, 1963, pág. 182.

$\mathrm{Si}$, según Porge, el estadio del eco precede al estadio del espejo, lo acompaña, y lo rebasa, entonces no podríamos mantener el circuito (con la flecha dextrógira); el pasaje no sería tampoco secuencial de 
este modo de operar de los objetos a que, como dijo Lacan, forman una estructura de conjunto. Sí, pero la voz no es un objeto más entre ellos, adquiere un valor distinto de la mirada y de las heces y del pecho, por el hecho de estar intrincado antes del espejo, durante el mismo y después del espejo. "[...] el eco no se superpone, ahí mismo ellos (estadio del espejo y estadio del eco) están intrincados. El eco no es la reduplicación de eso que pasa en el espejo" (2012, pág. 78, la traducción es mía) $)^{3}$.

Para que un niño pueda leer, primero ha de constituir su cuerpo imaginario. El cuerpo para tener unidad e integración ha de subjetivarse con una falta; pero antes de poder subjetivar una falta, el niño necesita saber a quién pertenece en la filiación y tener indicios del modo como les hace falta a sus padres. Si la falta no es subjetivada aparece en lo real y el cuerpo se vive como fragmentado o dislocado. Esta es una observación que se encontró en la literatura revisada, en la propia experiencia y en la de otros colegas. Si algunos aprenden a leer, lo hacen sin apropiarse del sentido, se limitan a seguir o repetir las grafías. La imagen inconsciente del cuerpo, como imagen en falta, es el saldo del segundo momento del juicio de existencia. Si un niño no ha podido realizar la segunda operación del juicio, puede vivir las letras como algo persecutorio, que le asusta y huye de la actividad. El cuerpo imaginario tiene una topología transitiva porque se construye en el transitivismo (Colín, 2016, págs. 203-219). La dimensión transitiva la llevamos puesta a lo largo de la vida, se refiere a esta relación pendular entre el yo y el otro. Inevitablemente necesitamos mirarnos en el otro, aunque también ahí reside su dimensión alienante.

El transitivismo fue descubierto en los infantes por observación de Charlotte Bühler y colaboradoras. Lacan se refiere a esta dimensión transitiva en su texto sobre el Estadio del espejo (Lacan, 2009/1936, pág.104) y en sus tesis sobre la agresividad (Lacan, 2009/1949, pág. 117). Un niño llora y de inmediato comienzan a llorar los otros. La falta de diferenciación entre un cuerpo y otro produce una suerte de "contagio". La voz también transita de una persona a otra entre quie-

3 “ [...] l'echo ne se superposent pas, là même où elles son intriquées. L'echo n'est pas la réduplication de ce qui se passe dans le miroir." 
nes guardan una relación significativa; la voz es transitiva y el cuerpo imaginario también. La letra y el cuerpo se entretejen. Por eso la reconfiguración del cuerpo imaginario forma parte de aprender a leer y escribir.

\section{Palabras finales}

La imagen inconsciente del cuerpo está reconfigurándose durante el análisis en el caso de adultos, y en la práctica analítica con niños esto también se produce. Esta reconfiguración de la imagen inconsciente del cuerpo se pone en juego también al aprender a leer y escribir, a juzgar por niños observados en entornos escolares, además de los niños atendidos dentro del dispositivo analítico.

El cuerpo es resultado de la resonancia de las voces parentales que el niño hace con su lalengua, es su primer ejercicio como ser hablante. Si la lalengua es resultado del malentendido de los padres y lo que ha malentendido (mal entendu y malentendu) el propio infante, y recoge además una brizna de goce fálico, el cuerpo es el archivo del lugar del niño en la filiación y porta trazos de la verdad que lo constituyen como ser deseado y deseante. Ese tejido se hace con la letra.

No puede haber acceso a la letra si la pulsión invocante -que comprende acoger la voz pero también hacerse escuchar- no se ha puesto en juego, esto implica haber subjetivado, en cierta medida, su falta. Los niños preescolares están en una relación con sus padres particularmente cercana e intensa. La lectura restará la autoridad de los padres, o la imagen omnipotente que el niño tenía de ellos, ya no serán la única fuente de saber. El niño preescolar ha de abandonar sus vínculos incestuosos, habrá de diferenciarse de la madre y de renunciar a ella como alguien que lo completaría; en algunos niños preescolares eso está lejos de ocurrir.

En el ámbito clínico he podido apreciar que algunos niños no pueden aprender a leer y a escribir antes de haber realizado las dos operaciones del juicio referidas antes (Freud, 1984/1925), indispen- 
sables para la formación de su yo. El juicio de existencia se produce gracias a la escritura de una pérdida, misma que procura la pulsión invocante. Ser adulto cronológicamente no significa haber recorrido todos los tiempos de la pulsión invocante, entre los que se cuenta hacerse escuchar. Para que el niño pueda comprender lo que lee ha de encontrar antes su lugar en la filiación, pues, como dice Porge, sin ello las letras no tienen sentido.

\section{Referencias}

Colín, A. (2016). El cuerpo, la noción lacaniana lalangue y el transitivismo. Revista Affectio Societatis, 13(25), 203-219. https:/ / revistas.udea.edu.co/ index.php/affectiosocietatis/article/view/324988.

Dolto, F. (1981). En el juego del deseo. Siglo XXI Editores.

Dolto, F. (1985/1949). La muñeca flor de Françoise Dolto. En: Jacques Miller, Intervenciones y textos. Editorial Manantial.

Dolto, F. (1990/1984). La imagen inconsciente del cuerpo. Editorial Paidós.

Ferreiro, E. (2007). Alfabetización de niños y adultos: textos escogidos. CREFAL.

Freud, S. (1978/1905). Tres ensayos para una teoría sexual. En J. Strachey (Ed.) y J. L. Etcheverry y L. Wolfson (Trads.), Obras completas (Vol. VII, págs. 109-224). Amorrortu Editores.

Freud, S. (1979/1900). La interpretación de los sueños. En J. Strachey (Ed.) y J. L. Etcheverry y L. Wolfson (Trads.), Obras completas (Vol. IV, págs. 3-343) Amorrortu Editores.

Freud, S. (1984/1900). La interpretación de los sueños. En J. Strachey (Ed.) y J. L. Etcheverry y L. Wolfson (Trads.), Obras completas (Vol. V, págs. 345-668). Amorrortu Editores.

Freud, S. (1984/1915). Lo inconsciente. En J. Strachey (Ed.) y J. L. Etcheverry y L. Wolfson (Trads.), Obras completas (Vol. XIV, págs. 153-213). Amorrortu Editores.

Freud, S. (1984/1925). La negación. En J. Strachey (Ed.) y J. L. Etcheverry y L. Wolfson (Trads.), Obras completas (Vol. XIX, págs. 249-257). Amorrortu Editores.

Freud, S. (1986/1895). Proyecto de una psicología para neurólogos. En J. Strachey (Ed.) y J. L. Etcheverry y L. Wolfson (Trads.), Obras completas (Vol. I, págs. 323-440). Amorrortu Editores.

Freud, S. (1986/1897a). Manuscrito M. En J. Strachey (Ed.) y J. L. Etcheverry y L. Wolfson (Trads.), Obras completas (Vol. I, págs. 292-295). Amorrortu Editores. 
Freud, S. (1986/1897b). Carta 50. En J. Strachey (Ed.) y J. L. Etcheverry y L. Wolfson (Trads.), Obras completas (Vol. I, págs. 273-274). Amorrortu Editores.

Freud, S. (1986/1901). Psicopatología de la vida cotidiana. En J. Strachey (Ed.) y J. L. Etcheverry y L. Wolfson (Trads.), Obras completas (Vol. VI, págs. 1-270). Amorrortu Editores.

Freud, S. (1986/1905). El chiste y su relación con lo inconsciente. En J. Strachey (Ed.) y J. L. Etcheverry y L. Wolfson (Trads.), Obras completas (Vol. VIII, págs. 9-223). Amorrortu Editores.

Hyppolite, J. (2009/1954). Comentario hablado sobre la Verneinung de Freud. En: Escritos 2 (págs. 837-846). Siglo XXI Editores.

Lacan, J. (1957-58). Séminaire 5. Les formations de l'inconscient (Sesión 23 de abril de 1958), versión Staferla. http://staferla.free.fr/S5/S5\%20FORMATIONS\%20.pdf

Lacan, J. (1963). Seminaire 10, L'angoisse (Sesión 19 de junio), versión Staferla. http://staferla.free.fr/S10/S10\%20L'ANGOISSE.pdf

Lacan, J. (1980). Séminaire 27, Dissolution (Sesión 10 de junio y Sesión 10 de julio). Versión staferla. http:/ / staferla.free.fr/S27/S27.htm

Lacan, J. (2009/1936). El estadio del espejo como formador de la función del yo (je) tal como se nos revela en la experiencia psicoanalítica. En T. Segovia (Trad.), Escritos (Vol. 1, págs. 99-105). Siglo XXI Editores.

Lacan, J. (2009/1945). El tiempo lógico y el aserto de certidumbre anticipada. Un nuevo sofisma. En T. Segovia (Trad.), Escritos (Vol. 1, págs. 193-208). Siglo XXI Editores.

Lacan, J. (2009/1948). La agresividad en psicoanálisis. En T. Segovia (Trad.), Escritos (Vol. 1, págs. 107-127). Siglo XXI Editores.

Lacan, J. (2009/1954a). Introducción al comentario de Jean Hyppolite sobre la Verneinung de Freud. En T. Segovia (Trad.), Escritos (Vol. 1, págs. 351361). Siglo XXI Editores.

Lacan, J. (2009/1954b). Respuesta al comentario de Jean Hyppolite sobre la Verneinung de Freud. En T. Segovia (Trad.), Escritos (Vol. 1, págs. 363378). Siglo XXI Editores.

Lacan, J. (2009/1957). La instancia de la letra en el inconsciente o la razón desde Freud. En T. Segovia (Trad.), Escritos (Vol. 1, págs. 461-495). Siglo XXI Editores.

Lacan, J. (2012). Lituratierra. Graciela Esperanza y otros (Trads.). Otros escritos (págs. 19-29). Editorial Paidós.

Porge, E. (1987). La dislexia como síntoma. Una fobia de la letra. Revista Litoral, 2-3, (págs. 111-139). 
Porge, E. (2011). Les voix, la voix. Revue Essaim/1, 26, 7-28. https://www. cairn.info/revue-essaim-2011-1-page-7.htm.

Porge, E. (2012). Voix de l'echo. Éditions Érès.

Porge, E. (2015). Entre voces y silencios. Torbellinos del eco. Revista Lapsus Calami, La Angustia y lo Unheimliche, 5, (págs. 109-124). 